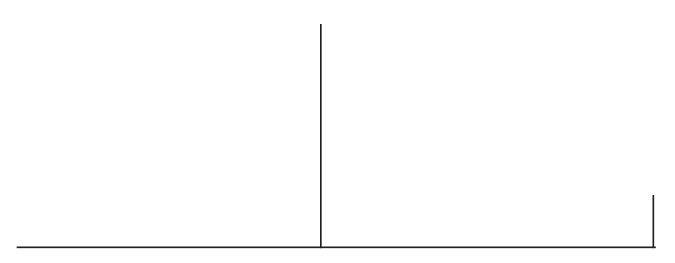

\title{
Entrevista com um vampiro
}

\author{
Júlio César Cordeiro do Nascimento
}

$O$ artigo relata uma entrevista inicial de análise, onde um discurso queixoso $e$ estereotipado acerca da homossexualidade dá lugar a um primeiro pedido de análise.

A partir de fragmentos clínicos $e$ elementos teóricos o autor vai questionar a tentativa falaciosa de compreender todo o sofrimento psíquico pela via de uma categoria identitária (homossexualidade) que, a rigor, é externa ao dispositivo analítico. $O$ analista se abstendo de qualquer valoração desta preferência amorosa desobtura sua escuta e permite a associação livre, abrindo espaço para o início da rememoração e para a emergência de outras significações e outros sofrimentos. 


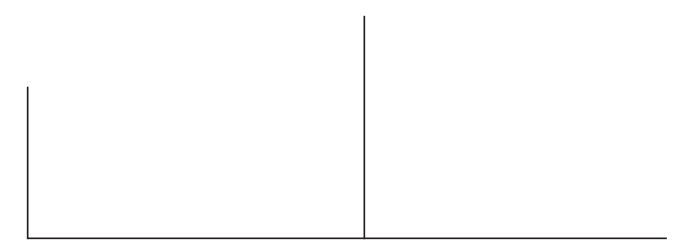

A entrevista que pretendo relatar aconteceu no Instituto Kaplan - Centro de Estudos sobre Sexualidade Humana no qual sou supervisor do Ambulatório de Sexualidades Alternativas.

Os pacientes que chegam a mim, portanto, procuram a instituição, passam por uma entrevista denominada triagem e são encaminhados ao ambulatório de Sexualidades Alternativas através de um prontuário. Tenho por procedimento encaminhar aleatoriamente estes pacientes aos terapeutas do meu ambulatório sem ler o relato da entrevista de triagem, levo em consideração apenas a compatibilidade de horários do terapeuta e aqueles períodos que o paciente colocou a disposição para a realização do tratamento. Uma vez que o paciente não pode escolher o analista, acho desaconselhável que pelo relato de outro se façam escolhas por um paciente imaginário. Seguindo um rodízio simples eu também recebo encaminhamentos.

Foi assim que Marcos chegou a mim...

Marcos entrou na sala, sentou-se e cruzou os braços de uma forma estranha, e desta forma meio imóvel permaneceu. Perguntei a ele porque tinha procurado o Instituto Kaplan, ao que ele respondeu surpreso: "Você não leu o relatório?" 
Eu disse que não e perguntei como ele sabia que havia algum "relatório". "A psicóloga disse que você receberia... Vou ter que repetir tudo?" (Desapontado, mais tarde soube pela psicóloga que Marcos havia feito um verdadeiro interrogatório sobre sigilo e procedimentos). "Concordo com você que é um saco repetir algumas coisas, mas prefiro ouvir dos próprios pacientes as suas queixas... A pessoa quando escreve sempre diz as coisas a seu modo, queria ouvir o que você tem a me dizer."

"Eu procurei o Kaplan pois minha mãe me indicou há uns 6 meses... E é difícil falar, mas eu sou homossexual..."

"Sim e daí..."

"E daí como?"

Ele então começa a falar aquilo que eu chamo em supervisão de "discurso do paciente Kaplan", este é um tipo de discurso repetitivo sobre o preconceito, Marcos fala que a sociedade discrimina, blá, blá, blá...

Confesso que não tenho paciência com esse discurso e nem consigo repetir o que o paciente disse.

Num dado momento, talvez percebendo o meu desinteresse:

"Mas antes de prosseguir, eu não posso continuar falando sem saber o que você pensa sobre homossexualidade..."

"Como assim?"

"Ah... Eu queria saber o que você pensa. Você acha que é uma doença?"

Fiquei meio sem jeito, pois a pergunta era meio incisiva, mas senti que aquela saída estratégica pela direita do tipo "É importante para você isso..." ou "Porque você quer saber?", não colaria. Decidi ser sincero: "Achei interessante você formular essa pergunta de forma direta, pois em geral o paciente se preocupa com isso, mas tenta ter a resposta sondando o analista. Eu tenho lido e pensado no assunto e a resposta mais verdadeira para mim é que a homossexualidade é um conceito criado por psiquiatras e pouco me ajuda na clínica, ser homossexual é o mesmo que ser Punk, Heavy Metal, é um estilo, um grupo social que compra e que está na mídia... A propósito gostaria de fazer-lhe uma pergunta, se você me diz que é homossexual há tanto tempo e esse teria sido o motivo de procurar um tratamento, se teve indicação dele há 6 meses, porque exatamente na semana passada você decidiu procurar e não antes?"

Ele passou a contar a sua história.

Marcos é um jogador de RPG (Role Play Games) e conheceu um rapaz num dos grandes eventos em São Paulo. Convidou-o para jogar mais vezes com outros amigos, segundo ele, foram vários encontros, ele ficou apaixonado pelo rapaz, pensava nele muito e fazia várias "fantasias de estar junto com ele", "como todo casal de namorados normal faz". 
$\begin{array}{lllllll}R & E & V & \text { I } & S & T & A\end{array}$

LATINOAMERICANA

DE PSICOPATOLOGIA

FUND A M EN T A L

Para entender sua história, fazia muitas perguntas sobre o que era RPG, Mestre (pessoa que propõe o enredo, os personagens, a trama do jogo, uma espécie de autor e diretor) e outros conceitos que ele usava, percebia um prazer dele em me explicar, percebi que ele ia relaxando e até descruzou o braço, recostando na poltrona.

Ele continua dizendo que ninguém sabe de sua preferência sexual, pois ele fala de mulheres e inventa o que ele chama de "máscara da heterossexualidade". Sua principal preocupação era saber se o rapaz era "hétero" e "se teria chance". Armou uma estratégia complicada para descobrir isso e o rapaz numa conversa com ele disse que "tinha vários amigos assim no teatro", mas que "tinha namorada e que não tinha nada a ver".

Marcos caiu em profunda melancolia, diz que se ele adorava RPG, sua única diversão, agora "gosta 50\% menos", pois associa RPG à sua frustração amorosa, "não tem vontade de fazer nada", as pessoas o percebem triste, mas ele acredita não poder dizer o que se passa com ele, sente que seu potencial no trabalho também caiu "de 50 a 70\%". Ao falar disso decide me exemplificar:

"Eu sou como um vampiro que precisa de sangue para viver, mas o vampiro tem uma regra número um: nunca revelar sua identidade, pois as pessoas, por achá-lo um monstro, vão destruí-lo, ao mesmo tempo, ele precisa de sangue e quando ele tenta saciar-se, revela-se, mas isso implica na morte do outro" (emocionado).

Neste momento, em milésimos de segundos se passaram várias coisas comigo, olhei para ele e percebi como era branco, pálido e sem vida, percebi como este mito estava tomando forma no seu corpo e na sua vida. Entretanto, achei bela a metáfora e constatei que ele resolveu tira sua máscara para mim. De súbito veio-me um pensamento defensivo. "Será que ele tirou a máscara porque me considera um vampiro como ele? Um analista-homossexual...". Pensei no hífen homossexual e nessa coisa que querem grudar nas pessoas o tempo todo. Mergulhei fundo e descobri que não era neste espelho que eu estava preso, mas sim, na lembrança da dor de amar alguém e não ser correspondido e pensei que talvez ele ainda não tivesse percebido que todos nós somos vampiros. Todos nós, por mais diversos que possam ser os caminhos da subjetividade, já tivemos algum contato com gotas do sangue da castração, desejar e não poder ser ou ter.

Disse a ele (lembrando o filme Entrevista com um vampiro, que eu curiosamente tinha reassistido exatamente na noite anterior - Marcos não soube da reapresentação do filme, mas relatou ter assistido este filme inúmeras vezes): "Sei que os vampiros se alimentam de ratos quando renunciam a beber sangue humano e se enfraquecem, vejo você enfraquecido, mas quais são seus ratos?" 
"No caso... os ratos são a masturbação e as fantasias, mas como você mesmo disse sinto que eu não tenho mais força, me sinto enfraquecendo e a minha vida não pode ser um RPG."

"Marcos, gosto de trabalhar com metáforas, acho que elas são uma forma de se comunicar, acho que pude estabelecer um contato com você e entender melhor o motivo que o traz aqui.

Só que as metáforas têm um limite, sobretudo quando elas envelhecem e não nos deixam mudar... da mesma forma que usamos a imagem dos vampiros, quem sabe surjam outras imagens."

"É... (pensativo) talvez eu possa criar novas metáforas, e viver mais minha realidade, eu queria recuperar minha energia, não quero me matar, mas não tenho vontade de fazer nada e nem o RPG, de que eu gostava tanto eu gosto mais..."

"E aqui por enquanto vai ser meio parecido com um RPG real, mas você será o mestre..."

Encerro a sessão.

A clínica tem me feito pensar que a homossexualidade é um hífen. Meus pacientes se narram professores-homossexuais, vendedores-homossexuais, amigos-homossexuais, filhos-homossexuais, ou seja, sua definição do Eu obedece a função $\mathrm{F}(\mathrm{S})=\mathrm{x}-\mathrm{h}$, onde lê-se a função de um sujeito $\{\mathrm{F}(\mathrm{S})\}$ é definida por qualquer atributo ou representação do eu (x) que estará sempre colada ao discurso hegemônico sobre a homossexualidade.

Este discurso será sempre justificado defensivamente pelo sujeito como aprendido socialmente e fruto do preconceito. Mas o que considero digno de análise é que há nitidamente uma internalização desta forma de ver o mundo. Quando se internaliza o hífen, parece que o mais importante é "saber quem é..." e "saber quem não é homossexual", "quem me apóia" e "quem me persegue", e qual a fórmula mais eficaz de lidar com a perseguição e como criar máscaras sociais. Mecanismos que consomem grande parte do tempo e da libido do sujeito. Mas este ainda poderá ser considerado um discurso militante qualquer. $\mathrm{O}$ que recebo em análise são pessoas que, além de estarem presas a esta lógica, precisam acreditar que seu sofrimento é causado, só pode ser compreendido e amenizado pela via de um saber sobre a homossexualidade. Assim, percebo que oferecer um deslocamento desta temática é permitir a emergência de rachaduras, como escreve Delouya (no seu último artigo para o laboratório): "Pareceu-me que algumas correntes associativas impunham-se, entremeando sua recitação, ameaçando revelar suas rachaduras..." O que acredito estar fazendo nas primeira entrevistas com estes pacientes é tentar cortar a recitação, e exigir o cumprimento da regra fundamental, em uma de suas várias versões: "Fale o que lhe ocorre, não o que o outro disse para você." 


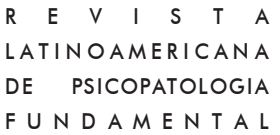

A este propósito penso que há duas coisas importantes: primeiro, o paciente sempre fala que "a sociedade pensa assim", "isso é o que a sociedade diz". Sigo logo a recomendação de Dolto sobre as entrevistas preliminares com crianças, perguntando: "quem disse isto para você? Pois nós não conversamos com a sociedade, conversamos com pessoas particulares". Essa sociedade vai sempre se transformar num amigo particular, no chefe do trabalho, no irmão, no pai ou na mãe.

Segundo, esses pacientes, na realidade, "recitam em pensamentos", pois na maioria das vezes eles não falam com ninguém, e acho que é fácil perceber a catástrofe psíquica que é acreditar que não se pode falar para ninguém de algo que o paciente acredita ser tão importante, que lhe causa tanto sofrimento e prazer.

A impossibilidade de dispor de modelos de identidade sexual publicamente discutíveis ou partilháveis por outros, torna os sujeitos homoeroticamente inclinados mais expostos aos riscos de infecção a AIDS do que aqueles que criaram alternativas identificatórias ao código heterossexual hegemônico (Costa, 1992). A impossibilidade de falar é associada à atuação, à compulsão sexual e à adição sexual. Logo, recitar com platéia já é um lucro, entretanto, cabe ao analista não se satisfazer com esse "show-off mambembe" e pedir para o paciente inventar um repente ali na hora, dispensando até a rima, ou seja, falar de si para um outro não referido a ideais tirânicos.

É tentando instaurar simplesmente a regra da associação livre que percebo que estes pacientes podem fazer um pedido de análise e como freqüentemente este pedido vem acompanhado de uma angústia mais primitiva.

Lembro-me do que Octávio Souza falou no último Congresso de Psicopatologia Fundamental, criando a partir das idéias de Balint: "Seria como se estes pacientes falassem de sexo para não falarem de ternura, de uma falha mais básica".

Esta atitude não consiste em proibir o paciente de falar de homossexualidade, mas sim em evitar fazer um papel complementar. A imagem que me ocorre é a de um vaqueiro que vive para tentar laçar os outros, o analista se oferece como boi (talvez boi de piranha), quando ele o enlaça, o analista, vazio e ausente como é seu lugar, desaparece, e o vaqueiro fica a se perguntar o que aconteceu com seu ritual defensivo.

Fédida (1988) chama isto de ocupar a posição de insistência do negativo, "desta maneira o paciente chega a descobrir que o negativo não é a morte..."

Penso que esses pacientes propõem um enamoramento romântico do tipo "estou apaixonado por você", ou "vamos aqui falar de como a sociedade é in- 
justa", ou "de como no começo, no meio e no fim da vida está a homossexualidade".

Fédida questiona:

O problema assim colocado, é preciso perceber o que Freud não percebeu aqui, isto é, enamorar-se do terapeuta não é simplesmente o momento em que o paciente vai falar de algumas coisas de que ainda não falou, ou por outra, enamorar-se, não é simplesmente resistência. É procurar uma situação de dominação, porque na evolução pessoal, o processo analítico começou a se abrir: o verdadeiro encontro com as angústias de morte arcaicas, o terror de um aniquilamento. Nessas condições o paciente se agarra ao terapeuta esperando fazer uma unidade com ele.

Cabe ao analista recusar-se a esse apelo unitário totalizante do Eu. Podemos acolher como verdadeiro aquilo que o paciente vive, mas não oferecer uma resposta atual. "O que chamamos de 'não resposta' é precisamente a recusa de dar o atual como resposta ao inatual." (Fédida, 1988)

Mas o que é o inatual?

Passei a indagar qual seria o efeito transferencial do discurso da homossexualidade sobre o analista. Penso que o analista se vê induzido na transferência a questionar a igualdade dos sexos, a diferença dos sexos, o que é ser igual, o que é ser diferente. $O$ analista fica angustiado por não saber onde reside a diferença entre masculino e feminino.

Parece possuir um valor heurístico o conceito de identidade de gênero nuclear de Stoller. Segundo este autor:

A identidade de gênero nuclear resulta, em minha opinião, do seguinte:

1. Uma "força" biológica: originando-se na vida fetal e comumente genética em sua origem, este efeito - tanto quanto se sabe - emerge da organização neurofisiológica (sistema nervoso central) do cérebro fetal;

2. A designação do sexo no nascimento: a mensagem que a aparência dos genitais externos do bebê leva àqueles que podem designar o sexo - o médico que está atendendo e os pais - e os efeitos inequívoco subseqüentes desta designação para convencê-los do sexo da criança.

3. A influência incessante das atitudes dos pais, especialmente das mães, sobre os sexo daquele bebê, e a interpretação destas percepções por parte do bebê - pela sua capacidade crescente de fantasiar - como acontecimentos, isto é, experiências motivadas, significativas;

4. Fenômeno "bio-psíquicos", efeitos pós-natais precoces causados por padrões habituais de manejo do bebê - condicionamento, imprinting ou outras formas de aprendizagem que nós imaginamos, modificam permanentemente o cérebro do bebê e o comportamento resultante, sem que os processos mentais do bebê o projetem deste input sensorial. Esta categoria está relacionada ao 
$\begin{array}{lllllll}R & E & V & \text { I } & S & T & A\end{array}$

LATINOAMERICANA

DE PSICOPATOLOGIA

FUN D A M EN T A L

ítem 3; ela é listada separadamente por uma questão de ênfase, e para distinguila dos processos mentais (também resultado das influências dos pais) com os quais nós estamos mais familiarizados, tais como a ansiedade de castração (Freud, 1909);

5. O desenvolvimento do ego corporal: a miríade de qualidades e quantidades de sensações, especialmente dos genitais, que definem o físico e ajudam a definir as dimensões psíquicas do sexo da pessoa, confirmando, assim, para o bebê as convicções dos pais a respeito do sexo de seu filho.

Podemos dizer, salvo nos casos onde há ambigüidade genital, que o médico e os pais designam - a partir dos genitais - o sexo da criança. Neste sentido, somente o primeiro ítem tem uma relação direta com questões propriamente biológicas, genéticas ou anatômicas, os quatro restantes referem-se a fatores externos e são de ordem propriamente significante, são efeitos da palavra dos pais.

Essa primeira nomeação tem uma força imaginária que forma a identidade de gênero nuclear. Sobre a influência da atitude dos pais, o bebê interpreta suas percepções e constrói sua imagem do corpo a partir dessa primeira diferenciação imaginária, que inclui o gênero em que o bebê é categorizado e o gênero dos pais em contrapartida. A identidade de gênero nuclear nada mais é do que o sentimento de ser homem ou ser mulher. Segundo Calligaris:

Na verdade quem leu Stoller lembra muito bem que ele sempre insistiu em que a distinção por ele proposta entre sexo biológico e identidade de gênero não tem nenhuma implicação do lado da escolha dos objetos sexuais dos indivíduos. A única conduta à qual podem dar lugar distúrbios de identidade de gênero, ou seja, essa discordância entre sexo biológico e identidade de gênero, é a aspiração transexual, o desejo de acabar transformando seu próprio sexo biológico de tal forma que corresponda à identidade de gênero.

Nesta direção, podemos pensar que o que determina o interesse de alguns indivíduos por pessoas da sua mesma identidade de gênero é obviamente o Édipo. Ou seja, o Édipo define quaisquer escolhas amorosas ou preferências sexuais subseqüentes do adulto. Assim, se existisse uma "causa da homossexualidade", esta seria a mesma causa da heterossexualidade, a saber, se quisermos compreender por que gostamos de pessoas que possuem tais e tais características, vamos vislumbrar um pouco dessas respostas rememorando nossa história edípica, história de escolhas e de identificações.

Mas por que persiste na clínica a fala de algumas pessoas que se deixam tomar por destinatários do discurso da homossexualidade, aceitam essa denominação, sentem-se diferentes das outras, consideram sua sexualidade desviante e/ou anormal ao olhar de um outro significativo e, em função disso, formulam a hipótese de que estes são os motivos de todo seu sofrimento? 


\section{ARTIGOS}

Podemos dizer que ninguém deixou que elas pensassem diferente, que isso é efeito de uma prática lingüística. Esta é uma hipótese provável, mas poderíamos nos perguntar também se esse discurso cultural não encontra eco ou ressonância em algum lugar do psiquismo.

A minha hipótese é a seguinte: nos dois a três primeiros anos de vida a criança é ensinada a acreditar que gênero e sexo anatômico são a mesma coisa, é esta convicção que Stoller denominou identidade nuclear de gênero. Nesse período, a criança também aprende a ver seus pais, figuras altamente significativas para ele, como um casal formado por uma pessoa do gênero masculino que mantém um relacionamento amoroso com uma pessoa do gênero feminino. Produz-se um deslocamento que torna a anatomia o pilar de sustentação narcísica do eu ideal, há um superinvestimento no anatômico, que escamoteia a questão das diferenças sexuais. Essa imagem de si e do casal parental, estrutura sustentada pelo imaginário sexual de nosso século, é atualizada na vivência particular da criança e outorgada pelos outros significativos, seus pais.

Ora, mais tarde a noção de masculinidade e feminilidade se amplia, se mistura e se complexifica a partir dos percursos mais idiossincráticos possíveis. Entretanto, quando um indivíduo que mantém relações amorosas com outro de seu mesmo sexo anatômico, ao ser interpelado pelo discurso preconceituoso da homossexualidade, sente ressonância desse discurso a partir daquelas primeiras nomeações primitivas. Assim, a representação de sua relação amorosa entra em conflito com a representação primeira do casal parental.

$\mathrm{O}$ Eu se identifica com a lógica do eu ideal do nosso século e acaba por se aprisionar numa posição narcísica de máxima desvaloração. A angústia mobilizada força o Eu a procurar respostas no discurso parental hegemônico. $\mathrm{Na}$ clínica, isto é o que os pacientes relatam com sendo: "eu descobri naquele momento que era homossexual".

Leandro, aos 12 anos, costumava ter brincadeiras sexuais com um rapaz mais velho. Isso não lhe angustiava até o dia em que ouviu sua mãe dizer, a propósito de um vizinho que tinha vida conjugal com outro homem, que eles eram bichas. "Naquele momento descobri que o que eu fazia era homossexualismo, que era errado e que meus pais jamais poderiam saber disso, o mundo desabou na minha cabeça e eu passei a evitar esses encontros" diz Leandro.

No decorrer de sua análise, Leandro pôde associar sua angústia com as forças pulsionais que, na sua adolescência, deixavam-no em uma posição de desamparo e pôde também rememorar seus desejos proibidos para com seus pais.

O que proponho ilustrar é que a fixação ego-narcísica no sistema de nomeação visa defender o sujeito do seu desamparo frente ao amor e à morte, ou seja, o discurso queixoso sobre a homossexualidade nada mais é do que uma 
R $\quad E \quad V \quad I \quad S \quad T$

LATINOAMERICANA

DE PSICOPATOLOGIA

FUND A M EN T A L

forma para evitar falar sobre as diferenças sexuais, na tentativa de driblar a castração. Pois sair da lógica do eu ideal significa abrir mão do olhar parental que nos coloca no lugar de "senhores do castelo", seria sair da fascinação do espelho que já aprisionou algum dia a todos nós.

Essa nomeação primitiva, que origina-se no imaginário sexual cultural, é filtrada pela personalidade dos pais e alcança o imaginário infantil quase que por imprinting, por "osmose", e que mais tarde na vida adulta entraria em conflito com a diversidade que é própria da sexualidade. Não se trata de uma militância politicamente correta, de coibir o uso dos termos gay ou homossexual, mas de questionar a suposição de que estas palavras designam uma psicodinâmica específica, o que justificaria hipóteses defensiva do sujeito, do tipo: "todo meu sofrimento é devido ao fato de eu ser homossexual". À medida que o analista é investido da mesma força pulsional que outrora era dirigida aos pais, abre-se um espaço para re-significar os conceitos de masculino e feminino na sua base mais primitiva, irracional e inconsciente. A palavra dita na transferência estaria na interface entre dois universos lingüísticos: o discurso social e o discurso psicanalítico. Na realidade, é o afeto que reconstrói essas significações. Oferecese ao analisando a oportunidade de construir novos sentidos para a sua forma de amar, que é tão singular e universal como todas as outras, deixando-o livre para entrar em contato com outros conflitos e questões de sua história, convidando-o para uma construção narrativa mito-poética, sustentada por uma fala mais próxima da sua verdade subjetiva.

Resumos

El artículo relata una entrevista inicial de psicoanálisis durante la cual un discurso quejoso y estereotipado acerca de la homosexualidad se transforma en un primer pedido de análisis.

Partiendo de fragmentos clínicos y elementos teóricos, el autor cuestiona el intento falacioso de compreender todo el sufrimiento psíquico por la via de una categoria identitaria (homosexualidad) que, a rigor, es externa al dispositivo analítico. Al abstenerse de cualquier valoración en relación a esta preferencia amorosa, el analista desobtura su escucha permitiendo la asociación libre, abriendo así espacio para el comienzo de la rememoración y para el surgimiento de otras significaciones y sufrimientos.

The article presents an initial pscho-analytic interview where a stereotyped and mournful discourse about homosexualism gives place to a first true request for analysis. 


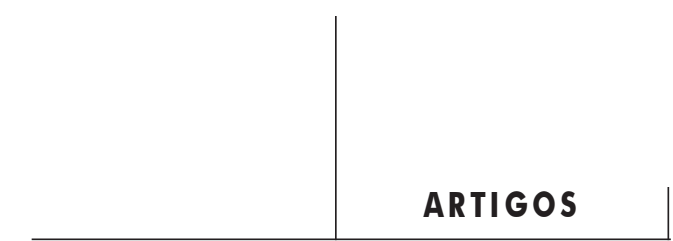

Based on clinical fragments and theoretical elements, the author questions the falacious attempt to understand all psychic suffering through a single identity category (homosexuality) which, in rigorous terms, is alien to psycho-analysis. By abstaining from any kind of value judgements regarding this sexual choice, the analyst disobstructs his capacity to listen allowing for free-association to occur, thus opening space for rememoration as well as the emergence of other significations and sufferings.

\section{Bibliografia}

Calligaris, C. (1996). “As diferenças sexuais". Boletim de Novidades da Livraria Pulsional, Ano IX, no 86, junho.

Costa, J. F. (1992). A inocência e o vício: estudos sobre o homoerotismo. Rio de Janeiro, Relume-Dumará.

FÉdida, P. (1988). Clínica psicanalítica: estudos. São Paulo, Escuta.

FReUd, S. (1914). "Sobre o narcisismo: uma introdução", in Edição Standard Brasileira das Obras Completas de Sigmund Freud, Rio de Janeiro, Imago. (1915). "Três ensaios sobre a sexualidade". Op. cit. (1921). "Psicologia de grupo e análise do ego". Op. cit. (1924). "A dissolução do cmplexo de Édipo”. Op. cit.

Stoller, R. J. (1993). Masculinidade e feminilidade: apresentação do gênero. Porto Alegre, Artes Médicas. 